International Journal of Medical Anesthesiology 2021; 4(1): 28-30

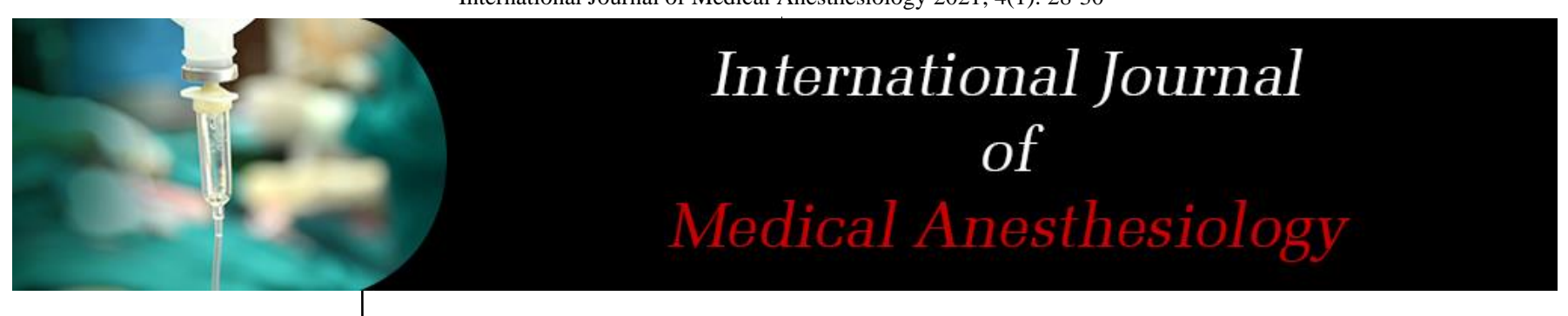

E-ISSN: 2664-3774

P-ISSN: 2664-3766

www.anesthesiologypaper.com

IJMA 2021; 4(1): 28-30

Received: 20-11-2020

Accepted: 25s-12-2020

Rakhi Gupta

Assistant Professor,

Department of

Anaesthesiology, Hind

Institute of Medical Sciences,

Barabanki, Uttar Pradesh,

India

Dr. Nishat Nasar

Assistant Professor,

Department of

Anaesthesiology, Hind

Institute of Medical Sciences,

Barabanki, Uttar Pradesh,

India
Corresponding Author:

Dr. Nishat Nasar

Assistant Professor,

Department of

Anaesthesiology, Hind

Institute of Medical Sciences,

Barabanki, Uttar Pradesh,

India

\section{A comparison of morphine versus fentanyl for postoperative analgesia after ambulatory surgical procedures}

\author{
Rakhi Gupta and Dr. Nishat Nasar
}

DOI: https://doi.org/10.33545/26643766.2021.v4.i1a.192

\begin{abstract}
Background: Morphine and fentanyl are widely used in ambulatory patients to provide analgesia during Phase I recovery in the post anesthesia care unit. The present study was conducted to compare morphine versus fentanyl for postoperative analgesia after ambulatory surgical procedures.

Materials and methods: 60 patients of ASA physical status I and II patients between 18 and 65 years of age undergoing ambulatory surgery of both genders were divided into 2 groups of 30 each. Group I received morphine and group II received fentanyl for postoperative analgesia. The drugs were administered in equipotent doses in the post anesthesia care unit (PACU) and were titrated against pain scores until a visual analog score.

Results: Group I had 14 males and 16 females and group II had 12 males and 18 females. The mean age in group I was 34.6 years and in group II was 38.2 years, weight was $72.5 \mathrm{Kgs}$ and $80.2 \mathrm{Kgs}$ in group I and II respectively and anesthetic duration was 58.2 minutes in group I and 68.4 minutes in group II. Operation performed was arthroscopy in 12 and 8 in group I and II respectively, shoulder surgery was 8 and 15 in group I and II respectively, elbow surgery was 10 and 7 in group I and II respectively. The difference was significant $(P<0.05)$.

Conclusion: Morphine produced a better quality of post- operative analgesia as compared to fentanyl.
\end{abstract}

Keywords: Morphine, fentanyl, post-operative analgesia

\section{Introduction}

After ambulatory surgery, persistent, intractable pain is one of the most common surgical complications. Adequate analgesia is necessary to facilitate same-day discharge of ambulatory patients whereas inadequate analgesia may delay or prevent discharge ${ }^{[1]}$. Recently, the range of procedures undertaken on an ambulatory basis has increased. More complex and painful procedures are being performed, which means the choice of analgesia is of greater significance in facilitating discharge ${ }^{[2]}$.

Local pain will be associated with incisions for the operative ports. Lower abdominal pain may depend on the extent of intraperitoneal manipulation during diagnostic laparoscopy. Sterilization operations cause ischemia or damage to the fallopian tubes and are generally more painful than simple diagnostic procedures, with clips generally causing less pain than other techniques to occlude the tubes ${ }^{[3]}$. Upper abdominal, shoulder tip, and postural high back pain after laparoscopy are likely to be caused by gas retained in the peritoneal cavity. Carbon dioxide is usually used to expand the abdomen to allow surgical visualization. Although it is a soluble gas in comparison to oxygen and nitrogen, it can take up to two days to be absorbed from the peritoneal cavity. Pain from the residual gas is of delayed onset and may present once the patient has gone home ${ }^{[4]}$.

Morphine and fentanyl are widely used in ambulatory patients to provide analgesia during Phase I recovery in the post anesthesia care unit ${ }^{[5]}$. As fentanyl has a faster onset time, its use may provide more rapid control of pain and avoid unnecessary extra does which may be administered when a drug of slower onset is used in small incremental doses titrated to pain ${ }^{[6]}$. The present study was conducted to compare morphine versus fentanyl for postoperative analgesia after ambulatory surgical procedures.

\section{Materials \& Methods}

The present study comprised of 60 patients of ASA physical status I and II patients between 
18 and 65 years of age undergoing ambulatory surgery of both genders. All were informed regarding the study and their consent was obtained.

Data pertaining to patients such as name, age, gender etc. was recorded. Patients were divided into 2 groups of 30 each. Group I received morphine and group II received fentanyl for postoperative analgesia. The drugs were administered in equipotent doses in the post anesthesia care unit (PACU) and were titrated against pain scores until a visual analog score. Type of operation performed was also recorded. Results thus obtained were subjected to statistical analysis. $\mathrm{P}$ value less than 0.05 was considered significant.

\section{Results}

Table 1: Distribution of patients

\begin{tabular}{|c|c|c|}
\hline Groups & Group I & Group II \\
\hline Drug & Morphine & Fentanyl \\
\hline M:F & $14: 16$ & $12: 18$ \\
\hline
\end{tabular}

Table 1 shows that group I had 14 males and 16 females and group II had 12 males and 18 females.

Table 2: Assessment of parameters

\begin{tabular}{|c|c|c|c|}
\hline Groups & Group I & Group II & P value \\
\hline Mean age (Years) & 34.6 & 38.2 & 0.06 \\
\hline Weight (Kgs) & 72.5 & 80.2 & 0.05 \\
\hline Anesthetic duration (min) & 58.2 & 68.4 & 0.02 \\
\hline \multicolumn{3}{|c|}{ Operations } \\
\hline Arthroscopy & 12 & 8 & 0.01 \\
\hline Shoulder & 8 & 15 & 0.04 \\
\hline Elbow & 10 & 7 & 0.91 \\
\hline
\end{tabular}

Table 2, Figure 1 shows that mean age in group I was 34.6 years and in group II was 38.2 years, weight was $72.5 \mathrm{Kgs}$ and $80.2 \mathrm{Kgs}$ in group I and II respectively and anesthetic duration was 58.2 minutes in group I and 68.4 minutes in group II. Operation performed was arthroscopy in 12 and 8 in group I and II respectively, shoulder surgery was 8 and 15 in group I and II respectively, elbow surgery was 10 and 7 in group I and II respectively. The difference was significant $(P<0.05)$.

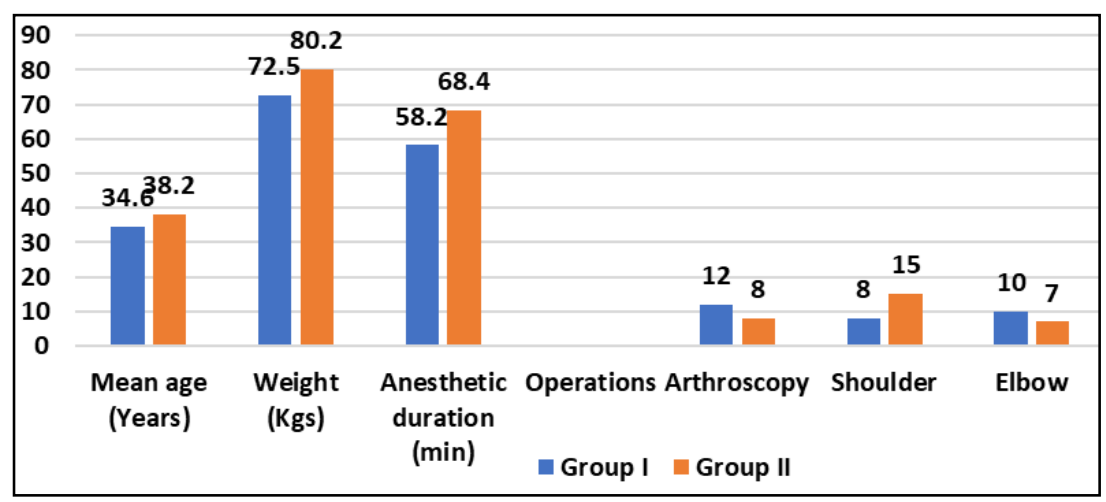

Fig 1: Assessment of parameters

Table 3: Assessment of VAS in both groups

\begin{tabular}{|c|c|c|c|}
\hline Duration (Minutes) & Group I & Group II & P value \\
\hline 10 & 70.2 & 68.7 & 0.12 \\
\hline 20 & 52.4 & 50.4 & 0.14 \\
\hline 30 & 38.4 & 46.2 & 0.02 \\
\hline 40 & 26.7 & 36.4 & 0.05 \\
\hline 50 & 15.2 & 26.6 & 0.01 \\
\hline 60 & 10.2 & 20.4 & 0.04 \\
\hline
\end{tabular}

Table 3, Figure 2 shows that mean VAS in group I and group II at 10 minutes was 70.2 and 68.7 , at 20 minutes was 52.4 and 50.4 , at 30 minutes was 38.4 and 46.2 , at 40 minutes was 26.7 and 36.4 , at 50 minutes was 15.2 and 26.6 and at 60 minutes was 10 . and 20.4 in group I and II respectively. The difference was significant $(P<0.05)$.

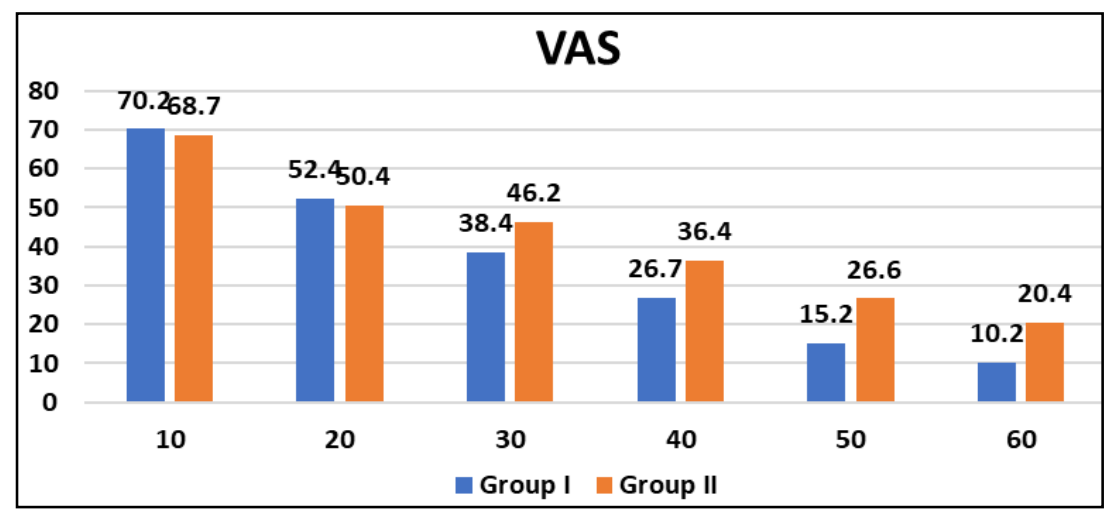

Fig 2: Assessment of VAS in both groups

\section{Discussion}

Pain in the immediate postoperative period often requires opiates. Alternatives, such as nonsteroidal antiinflammatory drugs or local anesthetic techniques, may be used, but these are not always possible for every patient or procedure ${ }^{[7]}$. Opiates will therefore continue to be an important part of the armamentarium available to provide rapid control of severe postoperative pain ${ }^{[8]}$. However, 
opiates have side effects, specifically nausea, sedation, and dizziness, which may delay the fitness of patients for discharge ${ }^{[9]}$. The present study was conducted to compare morphine versus fentanyl for postoperative analgesia after ambulatory surgical procedures.

In present study, group I had 14 males and 16 females and group II had 12 males and 18 females. The mean age in group I was 34.6 years and in group II was 38.2 years, weight was $72.5 \mathrm{Kgs}$ and $80.2 \mathrm{Kgs}$ in group I and II respectively and anesthetic duration was 58.2 minutes in group I and 68.4 minutes in group II. Operation performed was arthroscopy in 12 and 8 in group I and II respectively, shoulder surgery was 8 and 15 in group I and II respectively, elbow surgery was 10 and 7 in group I and II respectively. Claxton et al. ${ }^{[10]}$ in their study Fifty-eight patients undergoing ambulatory surgery were prospectively randomized to receive morphine or fentanyl for postoperative analgesia and studied in double-blind fashion. The drugs were administered in equipotent doses in the post anesthesia care unit (PACU) and were titrated against pain scores until a-visual analog score $<40 \mathrm{~mm}$ was achieved and the patient was satisfied with the level of analgesia. In the ambulatory surgical unit, oral analgesia was available. Pain scores, amount of analgesia used, the incidence of sideeffects (nausea and vomiting, sedation and dizziness), the times to achieve recovery milestones, and fitness for discharge were studied. Equal amounts of morphine and fentanyl were used in the PACU, but pain scores were higher in the fentanyl group in the ambulatory surgical unit. In addition, the fentanyl group required more oral analgesia than the morphine group (69\% vs $17 \% ; P<0.0002)$. The incidence of in-hospital side effects was similar. However, the morphine group had a more frequent incidence of post discharge nausea and vomiting than the fentanyl group (59\% vs 24\%; $P<0.016$ ). There was no significant difference in the duration of stay in the PACU (morphine vs fentanyl, $69+/-15 \mathrm{~min}$ vs $71+/-20 \mathrm{~min}$ ), the times to achieve recovery milestones, and fitness for discharge (morphine vs fentanyl, $136+/-41 \mathrm{~min}$ vs $132+/-40 \mathrm{~min}$ ). The short duration of fentanyl was not associated with faster discharge times; most patients required additional analgesia to control pain.

Opioids feature at the top of the World Health Organization's pain ladder and are usually used as part of the day-case general anesthesia, although a completely opioid-free technique should possibly be considered for patients undergoing minor surgery at very high risk of PONV. Opioids may be given pre-, peri- and postoperatively and may be short- or long-acting. Preoperative opioids have been trialed in day-case laparoscopic gynecological surgery. Both morphine and controlled release oxycodone given prior to induction have failed to reduce pain scores when compared to controls ${ }^{[11]}$. Morphine used perioperatively has a prolonged emetic effect, and the use of shorter acting synthetic opioids is more common. Research found that fentanyl was associated with less PONV compared to morphine, and this benefit extended into the period when the patients went home. However, patients in the fentanyl group required around two-and-a-half times the amount of supplementary oral analgesia, compared to those in the morphine group. Thus, if intraoperative morphine is used, consideration should be given to the prophylactic anti-emetics. ${ }^{12}$

\section{Conclusion}

Authors found that Morphine produced a better quality of post-operative analgesia as compared to fentanyl.

\section{References}

1. Wetchler BV. Postoperative management discharge and follow up. In: Weintraub and Levy, eds. Outpatient Anesthesia. Anesthesiology Clinics of North America, 5th ed. 1987:113-32.

2. Bodner M, White PF. Anti-emetic efficacy of ondansetron after outpatient laparoscopy. Anesth Analg 1989;73:745-51.

3. Chung F. Are discharge criteria changing? J Clin Anesth 1993;5:64S-68s.

4. Chung F, Chan VWS, Ong D. A post-anesthetic discharge scoring system for home readiness after ambulatory surgery. J Clin Anesth 1995;7:500-6.

5. Jarnberg PO, Wattwill M. IV morphine reduces gastric tone and causes more emesis than fentanyl in dogs [abstract]. Anesthesiology 1993;79:A371.

6. Carroll N, Miederhoff I', Cox F, Hirsch J. Postoperative nausea and vomiting after discharge from outpatient surgery centers. Anesth Analg 1995;80:903-9.

7. Kamath B, Curran J, Hawkey C, et al. Anaesthesia movement and emesis. Br J Anaesth 1990;64:728-30.

8. Pandit SK, Kothary S. Intravenous narcotics for premeditation in outpatient anaesthesia. Acta Anaesthesiol Stand 1989;33: 353-8.

9. Heine MF, Tillet E, Tseuda $\mathrm{K}$, et al. Intra-articular morphine after arthroscopic knee operation. $\mathrm{Br} \mathrm{J}$ Anaesth 1994;73:413-5.

10. Claxton, G McGuire, F Chung, C Cruise. Evaluation of morphine versus fentanyl for postoperative analgesia after ambulatory surgical procedures. Anesth Analg 1997;84(3):509-14.

11. Pandit SK, Kothary S, Pandit U. Comparison of fentanyl and butorphanol for outpatient anaesthesia. Can J Anaesth 1987;34:130-4.

12. Reisine T, Pastemak G. Opioid analgesics and antagonists. In: Hardman JG, Limbird LE, eds. Goodmans and Gilmans pharmacological basis of therapeutics. 9th ed. New York: Pergamon Press 1996, 521-56. 